\title{
Reformando a globalização:
criação de uma governança global independente
}

Rubens R. Sawaya

$\mathrm{E}^{\prime \prime}$ Making Globalization Work, o Prêmio Nobel Joseph Stigliz procura completar o trabalho que iniciou em $A g l o-$ balização e seus malefícios (2002), quando analisou o impacto das políticas liberalizantes do Consenso de Washington, e em Os exuberantes anos 90 (2003), no qual contrapõe a lógica liberalizante à política dos Estados Unidos e ao enfraquecimento dos Estados Nacionais ante o mercado financeiro e os interesses das grandes corporações. Com esse novo livro, o objetivo é propor reformas no modo como é gerida a globalização, para torná-la mais justa, minimizando seus malefícios e fortalecendo seus benefícios. Apesar de ser um livro mais propositivo do que analítico, é recheado de fatos e histórias extremamente interessantes que servem para melhor justificar suas propostas.

Torna-se um livro obrigatório não apenas pela riqueza e volume de propostas em si, mas pela análise das questões que dão corpo a elas. Além disso, porque nos coloca o seguinte desafio: é possível administrar a globalização? Em outras palavras, talvez pudéssemos dizer: é possível controlar o movimento do capital global materializado na ação das grandes potências e suas corporações multinacionais?

Em parte, o livro propõe repensar as reformas liberalizantes tipo "marketfriendly" aplicadas em diversos países, incluindo o Brasil, a partir do Consenso de Washington. Demonstra como essas estratégias geraram instabilidade e não desenvolvimento, diminuíram a sobera- nia dos países em desenvolvimento, enfraqueceram seus regimes democráticos pela imposição - de fora para dentro - de medidas $^{1}$ e valores inapropriados, e, no fim, têm criado um grande número de perdedores tanto nos países ricos como nos pobres, pelo desemprego que criam. Segundo o autor, esse é o resultado de um modelo imposto pelos países avançados por meio de instituições como FMI, Banco Mundial, OMC e Tesouro Norte-Americano de forma não-democrática, refletindo os interesses dos países desenvolvidos e de suas grandes corporações. "Sem um governo e instituições globais, nós temos um sistema de governança global caótico, sem coordenação" (p.21).

Lança à discussão um conjunto de propostas para administrar melhor a globalização. O autor acredita que é possível criar mecanismos para gerenciar a globalização a fim de promover o desenvolvimento mundial, garantindo que os interesses dos menos poderosos e dos países em desenvolvimento sejam de fato contemplados. Procura recuperar assim a famosa afirmação de Keynes (1978, p.126): "De minha parte, acho que, sabiamente administrado, o capitalismo provavelmente pode se tornar mais eficiente para atingir objetivos econômicos que qualquer outro sistema alternativo conhecido [...]". ${ }^{2}$ Para Stiglitz, pelos resultados já constatados, é possível afirmar que "Hoje, a defesa do 'fundamentalismo de mercado' desapareceu em larga medida [...] Sem regulação e intervenção 
apropriada do governo, o mercado não conduz à eficiência econômica [...] $\mathrm{O}$ desenvolvimento requer pensamento de longo prazo e planejamento" (p.XIV).

\section{Crítica à ortodoxia}

É importante destacar o esforço de Stiglitz em recuperar a tradição keynesiana - após de quinze ou vinte anos de neoliberalismo - contra a ortodoxia fundamentalista de mercado, segundo a qual o mercado é regido pelas mesmas leis da natureza. Para a teoria econômica, talvez isso seja o mais fundamental no livro: ${ }^{3}$ a retomada dessas idéias a fim de gerenciar o capitalismo; a constatação de que sem gerenciamento o sistema cria pobreza e desigualdade; a constatação de que o mercado só pode funcionar se administrado. $\mathrm{O}$ autor sabe que não é uma lógica nova, mas que é mais atual e consistente do que a lógica do Consenso de Washington. Além disso, já tirou o capitalismo de uma grande crise pelo menos uma vez.

Indo um pouco mais além, constata também que não existe uma única forma de pensar o desenvolvimento econômico que sirva a diferentes países com características diversas, ainda mais aquela que se diz baseada na economia norte-americana de "livre-mercado" que, na verdade, nunca foi livre e nem desvinculada de um Estado forte e atuante. ${ }^{4}$ Para o autor, países asiáticos como China, Japão, Cingapura são exemplos disso e souberam desenhar estratégias próprias dosando Estado e mercado. ${ }^{5}$ A América Latina fez tudo diferente da Ásia, e seu fracasso “junto com o sucesso da Ásia do Leste provê o mais forte argumentos contra o Consenso de Washington" (p.35). $\mathrm{O}$ fundamentalismo de mercado gerou muito mais problemas que soluções para o desenvolvimento mundial. "Chávez na Venezuela é o resultado [...]” (p.144).
As políticas liberalizantes e a privatização ${ }^{6}$ desmantelaram e enfraqueceram os Estados nacionais e a estrutura produtiva de países. O caso limítrofe foi a Rússia.

\section{A liberalização dos mercados}

Segundo o autor, nunca houve livrecomércio no sentido que os economis$\operatorname{tas}^{7}$ defendem.

O mundo de Adam Smith e do mercado livre que advoga que sob ele todos ficarão em melhor situação não é apenas um mundo mítico dos mercados funcionando perfeitamente, sem desemprego; é também um mundo no qual riscos não têm importância e podem ser evitados, a competição é sempre perfeita, sem Microsofts ou Intels dominando as áreas. (p.68)

Além de considerar que o livre-mercado é uma ficção, Stiglitz conclui que a liberalização comercial mundial se efetiva de forma injusta e assimétrica, "abrindo mercados nos países em desenvolvimento para bens dos países industriais avançados sem reciprocidade" (p.62). A assimetria a que se refere é resultado não apenas das diferenças de desenvolvimento industrial e tecnológico entre os países, mas também de poder de negociação, poder esse que está relacionado ao poder econômico. Para Stiglitz, raramente países em desenvolvimento conseguem de forma isolada um acordo que seja justo. Por isso, defende que os acordos bilaterais devam ser desencorajados.

Uma constatação relevante é que a efetivação do livre-comércio beneficia apenas as corporações multinacionais, ${ }^{8}$ uma vez que resulta em desemprego e elevação da pobreza tanto nos países pobres, pela destruição de capitais produtivos locais, como nos países ricos, pelo deslocamento das empresas para outros países. A perda de empregos ocorre em 
velocidade e volume mais elevado do que o ganho pelo desenvolvimento de novas atividades. Eleva, portanto, a pobreza tanto nos países pobres como nos de indústria avançada.

Além disso, para Stiglitz, a discussão sobre a liberalização comercial não está correta. Não é o livre-mercado que resulta em mais desenvolvimento dos países. A história tem demonstrado que é a elevação das exportações dos países pobres e não a remoção de barreiras à importação que tem promovido seu desenvolvimento. Da mesma forma, demonstra não ser verdade que é a política de liberalização de importações é que atrai investimentos estrangeiros, mas uma série de outros fatores. "O sucesso da China demonstra isso", afirma o autor (p.66). Por isso, defende a total abertura dos mercados dos países desenvolvidos aos subdesenvolvidos até que estes últimos possam competir.

À parte os inúmeros exemplos e análises de casos sobre o papel das instituições internacionais na forma desigual como o comércio mundial tem sido gerido em favor dos países mais ricos, Stigliz defende a modificação dessas instituições ou a criação de novas, independentes, para que os acordos sejam mais justos e promovam de fato o desenvolvimento global, permitindo aos países mais pobres alcançarem os mais ricos.

Outra questão importante é sua crítica aos acordos relativos aos direitos de propriedade (Trip). ${ }^{9}$ Para ele, esses acordos apenas "refletem o triunfo dos interesses corporativos dos EUA e União Européia” (p.105) no comércio internacional. Aponta que a garantia da propriedade intelectual não tem sido boa nem para os países desenvolvidos. Não é um instrumento eficaz para o desenvolvimento de novas tecnologias, ao contrário, freia-o ao estabelecer monopólio ${ }^{10}$ sobre conhecimentos muitas vezes adquiridos ao longo do tempo por diversas pesquisas financiadas com dinheiro público. Não tornar público determinado conhecimento leva à ineficiência produtiva, uma vez que impede a difusão da inovação. Impede também o desenvolvimento tecnológico dos países em desenvolvimento por transferência, bem como a diminuição da distância entre países ricos e pobres. Além disso, contraria a lógica da concorrência. Os países ricos criam monopólio sobre a mercadoria que têm para vender, ao mesmo tempo que defendem a liberalização em outras áreas.

\section{A questão dos países ricos em recursos naturais}

Preocupado com os conflitos latentes no mundo envolvendo países detentores de recursos naturais, principalmente petróleo, Stiglitz se pergunta qual a razão de os países que detêm essa riqueza serem pobres, possuírem grande disparidade entre ricos e pobres e terem sido (ou serem) dominados por ditaduras. Apesar de não relacionar a ditadura a interesses econômicos de grupos nacionais e internacionais, diretamente, aponta para o papel ativo nessa realidade das empresas multinacionais e das políticas de privatização desses recursos. Em ambos os casos, o fato é que têm sido garantidos os interesses tanto de grandes empresas como de consumidores globais e das elites locais que se beneficiam da exploração ou venda dos recursos (privatização), deixando a população desses países à margem. Corrupção tanto nos países como por parte das grandes empresas tem sido corriqueira. Isso é o que ocorre e ocorreu em países como a Venezuela. Lembra, assim, que a eleição de Chávez 
é uma resposta a esse histórico. "A habilidade de Chávez em negociar antigos contratos para melhorar seus termos para seu país, simplesmente, reforça a crença de que, no passado, os venezuelanos foram enganados" (p.144).

Para Stiglitz, os países ricos em recursos naturais devem assumir a maior responsabilidade por seu uso. A criação de instituições que zelem por normas internacionais para o uso desses recursos pode reduzir a corrupção tanto interna como externa e garantir seu bom uso. De qualquer forma, o autor sabe que mexer com esse assunto é tratar com interesses antagônicos dos países desenvolvidos e suas corporações, que têm por objetivo controlar os recursos naturais no mundo, mas acredita que instituições internacionais independentes podem minimizar o problema.

\section{$\mathrm{O}$ agravamento da questão ambiental}

A forma como a globalização tem funcionado, também, está contribuindo para uma acelerada piora nas condições do meio ambiente e no aquecimento global. O problema é que a poluição é gerada localmente, mas afeta o planeta como um todo. É uma questão típica de como ações micro criam externalidades negativas, em escala macro, no caso, planetária. Portanto, a solução só pode ser encontrada nesse âmbito e deve ser regulamentada de forma global e independente dos interesses de países ou de empresas específicas, na verdade, muitas vezes contrariando esses interesses.

Recursos naturais são bens públicos. A gestão privada desses recursos pode resultar em algum controle e preservação, segundo o autor, mas implica, sempre, uma distribuição menos igualitária dos recursos, muitas vezes permitindo o acesso a eles exclusivamente àqueles que têm renda mais elevada, os mais ricos. Propõe, assim, a criação de "alguma forma de gestão pública dos recursos naturais e a criação de um conjunto de regras globais sobre o uso e as externalidades negativas que esse uso gera" (p.165). Propõe ainda formas de punição econômica pela cobrança pelo uso, apesar de essa forma resultar em problemas semelhantes aos da privatização. De qualquer maneira, aponta que essas ações têm pouca chance de resultado se países como os Estados Unidos e a China não apoiarem. Mas propõe um sistema de sanções que, apesar de contrariar interesses, poderia talvez funcionar.

\section{O papel das grandes corporações}

Apesar de não apenas neste livro, mas nos anteriores aqui citados, o autor ter destacado o papel das grandes corporações na lógica do poder que tem feito a globalização funcionar de forma que seu malefícios se sobressaiam em relação aos benefícios, pouco toca nesse assunto quando se refere a elas diretamente. A despeito do que havia dito antes, agora reduz o mal que causam quase que exclusivamente a problemas éticos (destruição da concorrência, corrupção, uso indevido de recursos naturais, poluição) e não ao conjunto de determinações sociais, políticas e econômicas que decorrem de sua lógica de atuação e que põem em marcha o processo que denomina de globalização, sobre o qual realiza a sua crítica.

Assim, para ele, resolvendo-se esses problemas éticos relacionados a valores sociais por meio de uma contabilização pública - numa espécie de balanço social - para que a empresa seja julgada socialmente, bem como pela criação de alguns sistemas de punição a essas "externalidades", restariam, para o autor, apenas os 
benefícios que resultam da ação dessas corporações multinacionais, tais como a melhoria das condições de vida das pessoas pela criação de empregos, a transferência de tecnologia e conhecimento aos países menos desenvolvidos, e a promoção do crescimento econômico.

\section{A questão das dívidas externas}

$\mathrm{O}$ autor põe ainda em questão a forma de financiamento dos países menos desenvolvidos, recorrente fonte de crises financeiras e falências desses países, às vezes com potencial de desestabilizar todo o sistema. Para ele, trata-se de um problema de gestão: os países menos desenvolvidos tomam empréstimos além da sua capacidade de pagamento - por pressão ou não do sistema financeiro internacional -, e os credores não têm o devido cuidado, no momento de emprestar, dado o baixo risco que decorre da garantia dada pelo FMI. ${ }^{11}$ Ambos, credores e devedores, subestimam riscos de desvalorização cambial nos países tomadores ou de uma elevação dos juros internacionais. Ora, se é um problema de gerenciamento, ${ }^{12} \mathrm{o}$ autor propõe a formulação de contratos capazes de incluir os riscos, bem como a criação de um sistema de provisão para calamidades macroeconômicas (desvalorização ou elevação das taxas de juros internacionais) e a criação de controles sobre capitais especulativos. Uma estrutura de leis internacionais regulamentaria essas relações e estabeleceria a punição dos responsáveis, quando da ocorrência de crises de endividamento, evitando-se que o peso caia, exclusivamente, sobre os devedores como é hoje.

Uma vez, porém, deflagrada uma crise de endividamento externo, dentre as soluções propostas está a moratória, o que não é um ponto negativo para
Stiglitz, dado que o sistema financeiro internacional pensa, principalmente, no lucro e retorna quando o país começa a crescer. Uma outra solução é não adotar as políticas do $\mathrm{FMI}^{13}$ - "opostas ao que Keynes proporia" - focadas sempre no déficit fiscal, na elevação de impostos, no corte de despesas públicas. O caráter recessivo dessas políticas agrava o quadro. Além disso, muitas vezes as solicitações do Fundo vão além, forçando os países a adotarem a liberalização de capitais para atrair capitais externos, piorando ainda mais as coisas pela elevação da instabilidade desses países.

\section{A criação da moeda global}

Para o autor, o sistema de reservas globais atual tem sido perverso e tem criado uma instabilidade crescente nas finanças mundiais. Pensando nisso, de todas as propostas, talvez a mais interessante $\mathrm{e}$ polêmica seja a de criação de uma moeda global na direção do que havia proposto Keynes no pós-guerra. Stiglitz compreende que o sistema de reservas mundiais, tendo o dólar como centro, beneficia apenas os Estados Unidos ao disponibilizar-lhe recursos de baixo custo para financiar seu desequilíbrio comercial. ${ }^{14}$ Isso seria fonte de uma enorme instabilidade financeira internacional. Qualquer desconfiança no dólar pode fazer que países passem a manter suas reservas em outra moeda, o que poderia provocar uma crise de financiamento (se não uma corrida contra o dólar) dos Estados Unidos.

O sistema atual de reservas em dólar cria uma situação inusitada, na qual os países menos desenvolvidos acabam por financiar os Estados Unidos. "O que os Estados Unidos recebem dos países em desenvolvimento pelo sistema de reservas é mais do que eles fornecem a esses países como ajuda" (p.250). 
Assim, para solucionar esses problemas, Stiglitz propõe a criação de uma moeda internacional denominada "greenbacks", na qual todos os países converteriam suas reservas. Isso, segundo ele, teria enormes benefícios, tal como diminuir a instabilidade potencial do sistema financeiro internacional e, ainda, criar fundos para administrar crises e promover o crescimento e o desenvolvimento de países subdesenvolvidos. Outro benefício seria a redução do poder de algumas moedas especularem contra outras, dado que a taxa de câmbio seria definida pela instituição administradora.

Claro, o autor reconhece que isso traria problemas para os Estados Unidos, que teriam, então, que financiar seu déficit tomando empréstimos no mercado internacional, como qualquer outro país. Não toca em questões mais complicadas, como a diminuição do poder norteamericano que resultaria dessa medida, problema que nem Keynes conseguiu superar em um momento que esse país ainda se iniciava no papel de potência hegemônica mundial.

\section{A democratização da globalização}

O que Stiglitz defende neste livro, de fato, são mudanças na forma como é gerenciado o sistema global atual. Acredita que essas mudanças possam ocorrer pela democratização das decisões e das instituições internacionais, pela criação de um sistema de governança global, fazendo que os países menos favorecidos ou mais fracos consigam ter voz e possam, assim, se beneficiar da globalização, $\mathrm{o}$ que, até agora, pela lógica exclusiva do mercado, não ocorreu. De certa forma, no mesmo caminho das propostas de Keynes para administrar o capitalismo no âmbito dos países nos anos 1930, Stiglitz faz suas propostas, agora, em esca- la global, imaginando, talvez, a criação de um governo global desvinculado das grandes potências e das grandes corporações multinacionais.

O centro de sua discussão e de suas propostas está na revisão da relação entre Estado e mercado, na necessidade de intervenção pública de forma contundente, exatamente onde o mercado falha, no sentido de torná-lo mais próximo ao "perfeito", que pelo visto não são intervenções pequenas ou marginais. A questão é, portanto, como criar mecanismos e instituições capazes de zelar por essa governança global e promover o desenvolvimento de todos os países, ricos e pobres. Para ele, isso depende da capacidade de o mundo criar ou modificar instituições, fortalecendo as bases da democracia.

O que Stiglitz propõe no livro é bastante ousado e merece reflexão e consideração. Pode-se dizer que defende que se retire das mãos das grandes potências e de suas corporações multinacionais o controle que possuem sobre a globalização, responsável por grande parte dos malefícios que se abatem sobre o mundo atual. Resta pensar se isso é de fato possível, ou discutir o que suas propostas têm de real viabilidade e quais delas devem, mesmo que aparentemente inviáveis, ser um objetivo a perseguir. De qualquer forma, permanecerá a dúvida: será que é algo que poderia ocorrer, considerado o potencial de conflitos que envolve? Em síntese, será que mudar a forma como a globalização funciona não é mudar a forma como o capitalismo funciona?

O autor responde: "Este livro reflete minha fé na democracia; que cidadãos bem informados estão mais predispostos a realizar algum controle contra os abusos das grandes empresas e de inte- 
resses financeiros que têm dominado a globalização" (p.XIII). Vale lembrar que o trabalho que lhe deu o Prêmio Nobel dizia respeito às conseqüências para os agentes econômicos do fato de as informações serem sempre imperfeitas e limitadas.

\section{Notas}

l Segundo Stiglitz, o próprio FMI dá pouca importância à democracia dos países, uma vez que determina políticas econômicas de ajuste e a independência do Banco Central à revelia das decisões do próprio país. Utiliza como método deixar essas políticas a "técnicos" que tomam decisões independentes da política (p.56).

2 Diga-se de passagem que o outro "sistema conhecido" à época era o sistema soviético.

3 Esse aspecto parece estar ainda mais claro em seus dois livros anteriores, mas principalmente no segundo citado.

4 Demonstra isso claramente em Os exuberantes anos 90.

5 Poderia também relembrar as propostas da Cepal originais, mas não o faz.

6 Stiglitz, referindo-se inclusive ao caso do Brasil: "O argumento para a privatização é que o setor privado é mais eficiente do que o público. Esta opinião deve-se muito mais à ideologia do que a alguma análise bem feita [...] A ineficiência de algumas empresas estatais deve-se à falta de investimentos causada pela insistência do FMI em tratar as dívidas dessas empresas como dívida pública $[. .$.$] as empresas estatais dos países$ em desenvolvimento são efetivamente proibidas de fazer isso" (p.142).

7 Poderíamos acrescentar que muitos economistas trabalham com a hipótese de um mundo por eles idealizado, e formulam suas políticas não como base no mundo real, mas no que deveria ser modificado para se alcançar aquele mundo ideal.

$8 \mathrm{E}$ apenas no curto prazo, dado que não é sustentável no longo prazo por seus resultados.

9 Tratados relacionados a direitos de propriedade intelectual.

10 Narra exemplos histórico extremamente curiosos.

11 O chamado "risco moral".

12 Não relaciona esse problema, por exemplo, ao esquema de financiamento às próprias corporações multinacionais, às vezes amarrado à importação compulsória de equipamentos.

13 Segue teorias econômicas que têm sido "devastadoras para milhões de pessoas que vivem nesses países [devedores que adotam as políticas]" (p.235).

14 Não toca no ponto sobre o poder de Banco Central mundial que o Federal Reserve tem de, ao fazer a política monetária internacional, promover crescimento ou crises em outros países.

Referências bibliográficas

KEYNES, J. M. O fim do laissez-faire. In: SZMRECSÁNYI, T. Keynes, John Maynard: economia. São Paulo: Ática, 1978.

STIGLITZ, J. E. Making Globalization Work. New York: WW Norton, 2006.

Rubens R. Sawaya é doutor em Ciência Política, mestre em Economia Política, professor do Departamento de Economia da PUC-SP e autor do livro Subordinação consentida: capital multinacional no processo de acumulação da América Latina e Brasil (Annablume, 2006).

@ - rsawaya@uol.com.br 